\title{
A CONSTRUÇÃO DO CURRÍCULO EM PARCERIA COM O PROJETO EDUCATIVO
}

\author{
Mirian de Albuquerque Aquino
}

\begin{abstract}
Resumo
O presente texto propõe refletir sobre a construção de um currículo em sintonia com o projeto educativo frente ao cenário das mudanças tecnológicas. Insere uma discussão que articula educação e informação visualizando as mudanças possíveis na realidade dos cursos de formação humana. Mobiliza a complexidade dos saberes morinianos e as contribuições freireanas para tecer uma pedagogia da informação como uma alternativa que ajude a reduzir a ênfase no ensino repetitivo e suas técnicas convencionais. Propõe uma interação dos educadores e educandos com as novas formas de aprendizagem. Faz um "link" com autores que discutem as tecnologias da informação e comunicação e sua relação com a educação.
\end{abstract}

\section{Palavras-Chave}

Universidade; Projeto educativo; Currículo; Sociedade do conhecimento.

\section{INTRODUÇÃO}

Um novo modo de desenvolvimento vem criando novas formas de organização do trabalho, renovando as estratégias de produção e modificando as características do processo de inserção do trabalhador na máquina produtiva. Essa sociedade prioriza a informação como recurso econômico, o uso da informação pelo público em geral e a demanda de meios e serviços de in- formação. Essa dinâmica produziu uma expansão no campo da ciência, das técnicas e do saber, alterando as antigas formas de produzir, de conceber o trabalho e a formação profissional.

Conseqüentemente, essas alterações atingiram os conglomerados empresariais e os monopólios de produção, gerando o desemprego em massa, vez que se passou a priorizar um modelo de produção e em- 
pregabilidade cada vez mais alinhado às necessidades da economia informacional e global, cuja natureza do trabalho está se tornando intensiva em informação. Hoje, "o trabalho exige que os empregados absorvam uma grande parte do seu tempo no tratamento da informação e na tecnologia da informação" (MOORE, 1999, p. 96).

É verdade que as tecnologias da informação e comunicação (TIC's) aceleraram o processo de produção e aumentaram a quantidade de informação a ser acessada e processada, resultando numa demanda de produtos e serviços que exige constantemente recursos complexos e mentes qualificadas para atuarem em um mundo do trabalho altamente competitivo e diversificado. As inovações resultantes do avanço da ciência e da técnica mostram o valor agregado à informação, gerando novas qualificações e "uma demanda por profissionais que possuam competências, [habilidades] e conhecimento que até então não eram considerados necessários" (MOORE, 1999, p. 100).

Desde a década de 1960, os profissionais sentiram-se pressionados a reposicionar diante de seus afazeres para responder adequadamente aos desafios postos pelas tecnologias do trabalho com a informação. Em seu artigo intitulado "Educação e tecnologia: desenlaces/ (entre) laços na aventura de (in) formar o homem
- uma discussão possível?", Aquino (1995, p. 30) pensou uma categoria de profissionais da informação que engloba professores/as, bibliotecários/as e cientistas da informação que atuam em diferentes setores ligados ao campo da informação. Entretanto, nesse atual contexto em que o trabalho com a informação tornou-se mais complexo, ampliamos o nosso conceito de profissional da informação, de modo que bibliotecários/as, arquivistas, documentalistas, analistas de sistemas, cientistas da informação, editores e demais profissionais que lidam com a informação são, neste texto, entendidos como profissionais que pensam-conhecem-agem sobre a informação nos diferentes setores da sociedade da informação, conhecimento e aprendizagem (AQUINO, 2004).

Tais profissionais vêem-se compelidos a investir numa qualificação profissional compatível com as exigências de uma sociedade que, além do conhecimento dos princípios em que se baseia o trabalho da informação, requer as competências técnico-científicas para explorar plenamente o potencial tecnológico.

Até então, a formação desses profissionais revelava um caráter empresarial em parceria com as associações profissionais, e o ensino centralizava-se, sobretudo, no desenvolvimento de habilidades práticas. Nas décadas de 1970 e 1980, essa 
formação é deslocada das empresas para buscar nas universidades não só as competências necessárias ao mundo do trabaIho, mas a "compreensão teórica do trabaIho da informação" (MOORE, 1999)., requerendo uma modalidade de ensino, na qual a formação passa a ser entendida como uma mudança na percepção da natureza dos sujeitos envolvidos na relação informacional

$O$ avanço das TIC's repercutiu nas formas de conceber a educação, o ensino, a transmissão do conhecimento, o papel do/a docente e do/a discente, a formação do bibliotecário/cientista da informação e sua atuação no mundo do trabalho. Essas tecnologias "transformaram-se em um elemento constituinte (e até instituinte) das novas formas de ver e organizar o mundo", (ASSMANN; MO SUNG, 2000 , p. 270), estabelecendo uma "parceria cognitiva" na relação com o novo usuário da informação, e participando ativamente da transição da informação para o conhecimento.

As formas do aprender e do conhecer estabelecem sistemas cooperativos ou interfaces de parceria entre $o$ homem e a máquina, situando os aprendentes humanos no interior de uma ecologia cognitiva, em que a construção do conhecimento não é mais o resultado de uma ação isolada do homem, mas de uma vasta cooperação cognitiva distribuída por toda parte, em que participam aprendentes humanos e sistemas cognitivos artificiais (ASSMANN, 2000).

As escolas e as universidades foram desafiadas a experimentar os sistemas cognitivos estimuladores do "processo criativo do aprender" nas modalidades da educação presencial, semi-presencial e educação a distância. Há educadores/as solidários/as com a interferência desses sistemas, passando a investir em propostas de aprendizagem através de meios criativos emergentes e cooperativos, pois parecem entender que educar é criar condições para acessos a "experiências de aprendizagem". O resultado da educação não pode se resumir a saberes formais.

Convém, entretanto, que os sujeitos da aprendizagem assumam o papel de sujeitos interativos e críticos da informação com a qual trabalham, interagindo com outros sujeitos e com as tecnologias, posicionando-se, trocando experiências e gerando conhecimentos. E a Universidade, por sua vez, como instância formadora, "deve preocupar-se em criar e recriar as condições para que docentes e aprendentes se sintam em estado de apaixonamento por aquilo que irá proporcionar-lhes vida, ou seja, a unidade [...] entre processos vitais e processos de aprendizagem" (ASSMANN; MO SONG, 2000, p. 286). A nosso ver, essa compreensão de sujeito reflete na prática 
de formadores/as de profissionais da informação, trazendo-lhes a visibilidade de um projeto educativo como um vetor de conhecimento teórico e prático, capaz de conduzi-los/as a uma reflexão sobre as intenções, as preocupações, as expectativas e suas motivações na área de conhecimento em que estão inseridos. Por projeto educativo, entendemos a expressão de uma política de formação universitária que atua no sentido da qualidade de cursos de graduação, traduzindo as mudanças possíveis e necessárias ao ensino superior, exigidas pela reorientação da política educacional do País.

Em consonância com as atuais mudanças, os/as especialistas da educação (educadores/as, pesquisadores/as, técnicos/as etc) vêm promovendo debates em todas as áreas do conhecimento e aprofundando reflexões voltadas para a formação profissional. Essa dinâmica objetiva construir um projeto educativo ou projeto político-pedagógico que proponha uma nova concepção de currículo para atender aos objetivos e finalidades dos cursos de profissionais em formação. É uma estratégia que incorpora as diretrizes curriculares estabelecidas pelo Ministério da Educação e Desporto (MEC), as quais vêm permitindo que as Instituições de Nível Superior (IES) definam diferentes perfis profissionais para cada área do conhecimento e assegure-Ihes a flexibilidade de cursos e carreiras, e a integração do ensino de graduação com a pós-graduação. Com a nova LDB e a avaliação dos Cursos de Graduação, a SESU/MEC, através do edital n. ${ }^{\circ}$ 04/97, convocou as Instituições de Ensino Superior a apresentarem às Comissões de Especialistas as propostas para elaboração das novas diretrizes curriculares dos cursos superiores. Tomando como norte estas medidas legais, as discussões/análises estão sendo realizadas em todos os cursos do País, com vistas à redefinição curricular, que estabelecerá a organização de programas de formação, permitindo aos cursos de graduação uma flexibilidade na construção dos currículos plenos e privilegiando a indicação de áreas do conhecimento.

Ao definir esses perfis, contemplamse as competências intelectuais que refletem a heterogeneidade das demandas sociais em relação a profissionais de alto nível, construindo um modelo em que os cursos de graduação passam a ter um papel de formação inicial no processo continuo de educação permanente que é inerente ao mundo do trabalho. Para atender a essa exigência, reza o artigo 43 , inciso $V$, da LDB, a educação superior terá a finalidade de estimular o conhecimento dos problemas do mundo presente, em particular, os nacionais e regionais, prestar serviços especializados à comunidade e estabelecer com esta uma relação de reciprocidade. 
Do nosso ponto de vista, o currículo que possa atender aos objetivos propostos para a educação do futuro deve ser construído a partir de um projeto educativo. Ao formular sua proposta de educação libertadora, Paulo Freire refere-se à impossibilidade de pensarmos a transformação do mundo sem a elaboração de um projeto. Assim, não é possível sequer informar, se não construirmos um projeto que considere o global, o regional e o local.

Há cursos de formação que ainda não dispõem de um projeto educativo abrangente e formas de avaliação contínua por parte dos/as docentes e dos/as discentes, nem observam adequadamente $o$ aspecto da flexibilidade curricular no sentido de contribuir para a efetivação das mudanças necessárias à estrutura, organização e configuração exigidas aos atuais cursos de graduação.

\section{DESCONSTRUINDO O FORMATO CURRICULAR ENCAPSULADO}

A estrutura curricular do ensino superior no País revela a forte ingerência de uma governabilidade instrumental que secularmente permeia a educação, abrangendo suas políticas de ensino, teoria pedagógica, organização institucional e prática educativa. Essa problemática é parte também das preocupações de estudiosos da educação que a analisam, não só como uma questão que interfere na qualidade dos cursos de formação nas diferentes áreas de conhecimento, mas também como um entrave que retarda a inserção plena dos sujeitos na sociedade do conhecimento ou sociedade da aprendizagem.

A literatura especializada e as experiências educativas que servem de referência às análises de nossa realidade apontam que as mudanças curriculares, implantadas no território nacional nessas últimas décadas, mostraram uma letra quase perfeita, mas o espírito da coisa revela diversas lacunas nos limites de sua concretização. Evidencia-se, na prática, que as bases teórico-metodológicas propostas para a viabilização curricular não suportam as reais necessidades pedagógicas impostas pela cotidianidade da sala de aula.

Dentre as questões básicas que visavam a melhoria do ensino em cursos de formação, o currículo mínimo, implantado na década de 1980 como uma proposta estabelecida para cursos de formação, desconsiderou as novas exigências impostas pelo mundo do trabalho. Nesses cursos, os conteúdos ensinados contrastavam-se com o aprendizado da vida cotidiana, representando os valores econômicos e sociais modernos.

A face tecnicista que revestia os cursos de formação profissional tendia a reduzir a visão de que o currículo é a essência 
do projeto educativo construído com a inclusão do fazer e do pensar cotidiano sobre os conteúdos trabalhados nas instituições formadoras e nas suas atividades pedagógicas. É com razão que autores como Pourtois e Desmet (1999, p. 41), a partir dos postulados morinianos, chamam a atenção para os ranços tradicionais da prática educativa e a necessidade de inovar o ensino, afirmando que "a barbárie dos tempos modernos resulta do pensamento simplificador das concepções científicas herdadas (especialmente do positivismo) pelas quais a pedagogia sacrificouse durante muito tempo" e estabeleceu seus currículos. O currículo é, pois, uma mediação básica na formação profissional, vez que permite aos cursos atender às exigências da sociedade da qual faz parte e repensar o compromisso com as mudanças que ocorrem numa realidade fundamentalmente tecnológica.

Pesquisas educacionais mostram que um número considerável de docentes parece entender que a socialização do conhecimento ocorre com a simplificada informação conteudística, sem compreender que a educação é emancipação, capacidade de produzir (DEMO, 1995), e que interagir com a informação é também identificar-se com os meios tecnológicos, produzir sentido, gerar novo estado de conhecimento e participar da transformação da sociedade, norteando a vida acadêmica por um princípio científico e educativo, ou seja, por uma estratégia de geração, tratamento e uso da informação como coadjuvante à construção do conhecimento e a conquista da cidadania.

Portouis e Desmet (1999, p. 41) alertam que "toda idéia simples precisa ser revisitada, o que nos permitirá ingressar na complexidade que envolve a prática pedagógica". Para enfrentar o reducionismo pedagógico na composição dos conteúdos (saberes) necessários à formação do profissional da informação, é preciso que nos destituamos dos velhos hábitos acadêmicos para imiscuir-nos na transformação de uma nova pedagogia que se opõe:

A relação envelhecida ensino/aprendizagem, esconde, ainda, a cultura formalista que nos marca historicamente, sempre apta a encobrir sistemas de desigualdade crescente. [Nessa prática], o professor não se define por produção própria, domínio de conteúdos, capacidade de contribuição original, habilidade construtiva propedêutica, mas por uma forma geralmente vazia e que denota apenas o investimento de uma posição de autoridade (DEMO, 1995, p. 158).

A atual proposta de conteúdo do currículo afigura-se como um avanço para a formação do profissional da informação, permitindo que os cursos possam descentrar a concepção de currículo em que os indivíduos têm sido vistos simplesmente em sua capacidade de obter conhecimentos, quando deveria exercitar a capacidade 
de ressignificar esses conhecimentos por meio de "uma atitude reflexiva e questionadora, aprendendo a se posicionar diante da realidade numa atitude filosófica em relação à sua própria identidade e às situações que o circundam" (GRISPUN, 2001, p. 27).

O processo formativo é uma atividade complexa, porquanto implica não só a competência pedagógica, lingüística, ética e social, mas também o reconhecimento do outro como sujeito, saber de suas necessidades informacionais. O que significa, pois, formar profissionais que pensam-conhecem-agem sobre a informação? Do nosso ponto de vista, formar profissionais sobre a informação é desestabilizar nossas certezas sobre a informação que temos; formar profissionais é buscar o significado da informação, através de novos estudos e pesquisas para, conjuntamente com o outro, ressignificá-la e gerar novos conhecimentos.

Formar profissionais que pensamconhecem-agem sobre a informação, portanto, não é uma atividade solitária, mas reside exatamente na competência de organizar o currículo, considerando os alunos como aprendentes e portadores de objetivos, posicionamentos, conteúdos e/ou experiências referentes às informações focalizadas, tornando envolvente o processo ensino-aprendizagem (PENTEADO, 1998).
Formar profissionais é saber que a informação não pode ser uma receita pronta, mas implica "o desafio de criar, mudar, refazer" por que a informação e o conhecimento decorrentes dela estão sujeitos ao "erro e à ilusão" (MORIN, 2002).

Um contraponto à educação, que dificilmente atende aos interesses da atualidade, é vista no "Programa da Sociedade da Informação no Brasil: Livro Verde" um olhar sobre a positividade das TIC's no processo educacional, construindo uma pergunta cuja resposta aponta para as várias possibilidades de dinamizar o ensino e imprimir novas formas de ensinar:

$O$ que se pode fazer com tecnologias de informação e comunicação em educação? [...] Além de propiciar uma rápida difusão de material didático e de informações de interesse para pais, professores e alunos, as novas tecnologias permitem, entre, outras possibilidades, a construção interdisciplinar de informações produzidas individualmente ou em grupo por parte dos alunos, 0 desenvolvimento colaborativo de projetos por parte de alunos geograficamente dispersos, bem como a troca de projetos didáticos entre educadores das mais diferentes regiões do país (TAKAHASHI, 2000, p. 46).

As relações das TIC's com a formação profissional não desqualificam o ensino, o desenvolvimento da cognição e a formação crítica, mas "ajudam a intensificar o pensamento complexo, interativo e transversal, criando novas chances para a sensibilidade solidária no interior das próprias 
formas de conhecimento" (ASSMANN, 2000, p. 7).

\section{AS LUZES MORINIANAS ILUMINANDO A EDUCAÇÃO DO FUTURO}

O terreno da educação, muitas vezes, legitima os saberes prontos e acabados. Essa percepção está na base do pensamento moriniano, quando propõe saberes como possibilidades para construirmos a educação do futuro que deverá ser pensada como prioridade de toda sociedade e de toda a cultura, observando-se os modelos e as regras peculiares a cada sociedade na construção de seu projeto.

Essa construção do projeto pressupõe um saber que implica ver as cegueiras do conhecimento: "o erro e a ilusão". Este primeiro saber possui um conteúdo profundo a ser apreendido por aqueles/as que fazem a educação. Nesse sentido, Morin (2003) afirma "que é problemático subestimar o erro e a ilusão do conhecimento, pois a própria teoria da informação mostra que existe o risco de erro causado por efeito de perturbações aleatórias ou de ruídos em qualquer transmissão de informação, em qualquer comunicação da mensagem“ (MORIN, 2003, p. 20). Portanto, o educador do futuro (profissional da informação) deverá mostrar para alunos/as que não existe conhecimento que não esteja ameaçado pela inverdade. A prática docente supõe a consciência de que precisamos instrumentalizar adequadamente o/a educando/a, a fim de que possa identificar e questionar "as cegueiras do conhecimento do humano, seus dispositivos, enfermidades, dificuldades e as tendências ao equívoco" (MORIN, 2003, p. 20)

É preciso apropriar-se de um saber que implica considerar os princípios do conhecimento pertinente e alimentar a idéia de que aqueles/as que fazem a educação precisam tomar ciência dos problemaschave do mundo para terem acesso ao conhecimento, articular e organizar as informações, e perceber a necessidade de um entrelaçamento entre o contexto, o global, o multidimensional e o complexo. Esse conhecimento tem como exigência a reforma de pensamento que norteia o modelo educacional vigente, pois há neste uma compartimentação dos saberes que o dissociam dos problemas cotidianos.

Para Morin, "existe inadequação cada vez mais ampla, profunda e grave entre, de um lado, os saberes desunidos, divididos, compartimentados e, de outro, as realidades ou problemas cada vez mais multidisciplinares, transversais, multidimensionais, globais e planetários" (MORIN, 2003, p. 36). É evidente que essa inadequação que fragmenta os saberes apaga as relações que devem existir entre o contexto, o global, o multidimensional e o complexo. 
Morin destaca um conjunto de necessidades que devem ser consideradas na construção dos saberes e conteúdos para o ensino do futuro, tais como: situar as informações e os dados no contexto para que adquiram sentidos; estabelecer uma relação com o global; compreender o ser humano em suas múltiplas dimensões (biológica, psíquica, cultural, social, afetiva e racional) e a sociedade em suas dimensões histórica, econômica, sociológica, religiosa; enfrentar a complexidade, ligando os diferentes elementos e, ao mesmo tempo, mantendo a interdependência e a unidade na diversidade e; observar a multidimensionalidade humana, trabalhando essas dimensões, pois o papel da educação do futuro deverá ser a promoção da "inteligência geral" nesse contexto global.

O autor propõe um saber que mostra o ensino como uma condição humana, acenando para os profissionais que atuam em cursos de formação, conduzindo-os/as para a finalidade da educação, pois educar é formar o outro, e formar o outro implica mobilizar a compreensão para nossa condição humana (cósmica, física, terrestre) e interrogar sobre nossa posição no mundo. Significa conhecer o outro, ensinando-lhe a identidade humana para que reflita sobre nossa posição no mundo. E para conhecer o outro, é preciso ensinar-lhe a identidade humana para enxergar os problemas da sociedade do seu tempo e agir, desenvol- vendo as várias dimensões da consciência (ecológica, antropológica, cívica, terrena e espiritual).

Educar para o presente e o futuro significa repensar o papel da universidade como promotora do "grande remembramento dos conhecimentos oriundos das ciências naturais, a fim de situar a condição humana no mundo dos conhecimentos derivados das ciências humanas para colocar em evidência a multidimensionalidade e a complexidade" (MORIN, 2003, p. 48). Significa, para Morin, integrar na educação do futuro a contribuição das humanidades, vez que não apenas as disciplinas técnicas formam, mas também a literatura, a poesia, as artes, o lúdico etc são fundamentais.

Uma educação do futuro terá de cuidar para que a idéia da diversidade cultural não apague a da unidade, mas possa religar-se tanto à esfera individual quanto à esfera social. Essa educação terá de mostrar o destino humano como algo entrelaçado e inseparável, bem como a vocação do/a educador/a deve estar centrada no exame e no estudo da complexidade humana.

As reflexões de Morin falam-nos de um saber que implica ensinar a identidade terrena, conduzindo à reflexão sobre os nossos problemas e a realidade na qual nos inserimos, indicando-nos que a educação do futuro deverá estar fundada na 
compreensão da condição humana e da condição do mundo, reconhecida na perspectiva de uma condição planetária. Essa educação, segundo Morin, precisa atentar para a "intersolidariedade complexa dos problemas, antagonismos, crises, processos descontrolados [tomando como questão o que passa no mundo, seus] ingredientes múltiplos, conflitivos" (MORIN, 2003, p. 64). Essa postura supõe a competência para "contextualizar e globalizar", a qual implica que nos rendamos a uma reforma de pensamento, que englobe o policêntrico capaz de apontar o universalismo consciente da unidade/diversidade da condição humana, capaz de nutrir-se "das culturas do mundo" (MORIN, 2003).

A finalidade da educação do futuro terá a função de trabalhar a identidade e a consciência terrena, ensinando o indivíduo a aprender a 'estar aqui' no planeta, aprender a viver, a dividir, a comunicar, a comungar com as culturas singulares. Ensinar passa a ser um exercício de compreensão e de desenvolvimento de vários níveis de consciência (antropológica, ecológica, cívica terrena, espiritual da condição humana).

Trata-se de um saber que implica enfrentar as incertezas como um desafio educativo, convocando os ensinantes a responsabilidade de preparar alunos/as para o inesperado, as surpresas, os imprevistos, as indeterminações. Há uma necessidade de que a formação do/a educando/a aponte a incerteza do real, do conhecimento e da necessidade de precaução diante das verdades absolutas. Essa educação terá de captar o conhecimento e ensinar o/a educando/a a lidar com as incertezas, reconhecendo os princípios do processo de tradução/reconstrução próprio a todo conhecimento, do questionamento à lógica do conhecimento e percebendo a racionalidade a dificuldade de realização do autoexame crítico Nesse sentido, o/a docente pesquisador/a terá de estar convicto/a de que "a consciência do caráter incerto do ato cognitivo constitui a oportunidade de chegar ao conhecimento pertinente, o que pede exames, verificações e convergência de indícios" (MORIN, 2000, p. 86).

Muito mais que isso, a formação exige um saber que deseja ensinar a compreensão e traz o problema do ensino da compreensão que deverá ser uma das finalidades da educação do futuro, pois não há nenhuma técnica de comunicação que possibilite o exercício da compreensão. Educar para a compreensão significa encontrar nela a missão espiritual da educação, que é ensinar a compreensão entre as pessoas como condição e garantia da solidariedade intelectual e moral da humanidade. Compreender significa agir duplamente, captando, de um lado, a compreensão entre os humanos, os encontros e re- 
lações que se multiplicam entre pessoas, culturas, povos de diferentes origens. Do outro, é preciso observar que as relações particulares entre próximos são problemáticas, pois podem "alimentar malentendidos, ciúmes e agressividades, mesmo nos meios aparentemente mais evoluídos intelectualmente" (MORIN, 2003, p.94).

Duas formas de compreensão para instaurar a educação do futuro são propostas na discussão de Morin: a compreensão intelectual objetiva e a compreensão intelectual intersubjetiva. Por apresentar um aspecto material, a compreensão intelectual objetiva envolve a empatia, identificação e projeção, tornando-se insuficiente para a compreensão humana. A compreensão intelectual intersubjetiva envolve abertura, simpatia e generosidade e extrapola a inteligibilidade e explicação. No entanto, essa última é difícil de ser exercitada, vez que a compreensão de nós mesmos e de outros é cercada por barreiras econômicas, lingüísticas, sociais e culturais, as quais obstaculizam as idéias, visão de mundo e ação, produzindo alguns problemas na sua realização.

Um desses problemas, segundo Morin (2003), é que, na transmissão da informação pode haver a geração de ruído que interrompe a transmissão da informação com a intenção de gerar o mal entendido ou não-entendido. As diversas interpretações do conteúdo dessa informação em algumas situações podem causar dubiedade daquilo que se pretende transmitir. Nessa transmissão, nota-se a polissemia das palavras que, enunciadas em um sentido, podem ser entendidas de outra forma, conduzindo a certos problemas de compreensão.

Para Morin, o desconhecimento dos ritos, costumes e valores de outras culturas leva, muitas vezes, à tentativa de desvalorização de certas práticas ou mesmo ao desrespeito do outro. A impossibilidade, por despreparo intelectual ou limitações cognitivas, dificulta compreender as idéias ou os argumentos de outra visão de mundo, tornando as pessoas intolerantes e antiéticas. E, finalmente, a impossibilidade de compreensão de uma estrutura mental em relação à outra.

É um saber capaz de reconhecer uma ética do gênero humano que sinaliza para o exercício da ética da solidariedade. Segundo Morin, a ética humana (antropoética) supõe não só o indivíduo, a sociedade e a espécie, mas também a decisão de assumirmos a condição humana na complexidade do nosso ser para que alcancemos a humanidade em nós mesmos, em nossa consciência pessoal. É necessário que assumamos o destino humano em suas antinomias e plenitude, e trabalhemos 
para a humanização da humanidade. É fundamental respeitarmos no outro, ao mesmo tempo, a diferença e a identidade, quanto a si mesmo. Educar para o futuro significa, pois, desenvolver a ética da solidariedade, da compreensão e do gênero humano.

Blanchet (2002), abordando o tema Conhecimento da Terra e Educação, afirma que é preciso lembrar incessantemente que o despertar do espírito crítico é uma das principais finalidades da educação, pois entende que educar não se trata de acumular conhecimentos, mas sim, de formar a capacidade de julgar. Para ele, "o aluno deve fazer a experiência de uma análise racional que visa separar o verdadeiro do falso, ele deve aprender a evitar o erro, a desafiar a credulidade, a evitar os julgamentos precipitados, a não afirmar nada até que tenha reconhecido alguma legitimidade racional" (BLANCHET, 2002, p. 146).

Essa incursão pelo pensamento moriniano permite alargar nossa visão para as implicações educacionais desses saberes nos cursos de formação de profissionais que pensam-conhecem-agem sobre a informação. Essa formação é uma tarefa a ser assumida por educadores/os envolvidos/as numa construção coletiva e transformadora, que avance nas idéias. Para Blanchet (2002), “existe aí um desafio a ser enfrentado pelos que lecionam", ou seja, um desafio que

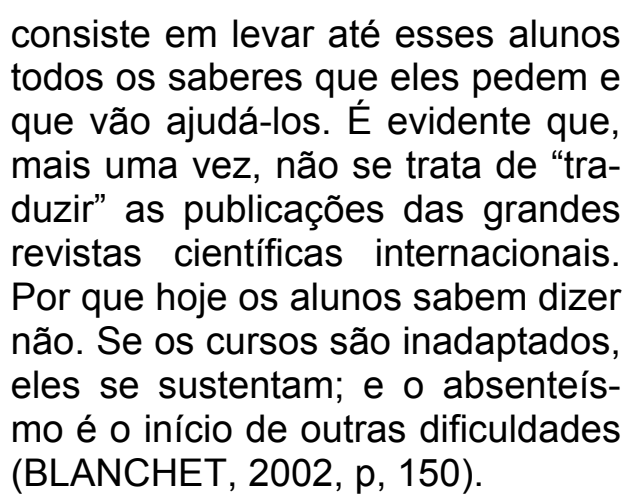

Independente da área de conhecimento em que estiverem atuando, a tarefa dos/as profissionais que pensamconhecem-agem sobre a informação segundo Blanchet, "é saber cativá-los, colocando ao alcance [dos/as alunos/as] tudo que pode contribuir para a apreensão do conhecimento necessário à formação científica, pessoal e cidadã" (BLANCHET, 2002, p. 150). Mas essa educação somente poderá ser instaurada a partir de um projeto educativo voltado à formação desses profissionais. Esse projeto deverá se preocupar não só com a formação para atuação em ambientes de informação (empresas, museus, arquivos, bibliotecas, editoras), mas também em dispor de conteúdos pedagógicos adequados, pois muitos desses profissionais atuam no campo da educação, sem os saberes necessários à formação do/a educando/a, aprisionando-o numa formação eminentemente técnica.

Os pressupostos mais amplos, que alicerçam a construção de um projeto edu- 
cativo em cursos de formação de profissionais que pensam-conhecem-agem sobre a informação, devem considerar os desafios colocados pela conjuntura global e o impacto do desenvolvimento tecnológico na comunicação, na geração, no tratamento, no uso e na disponibilização da informação.

As TIC's repercutiram no trabalho, na economia e na educação, favorecendo outras formas de acesso à informação e outros estilos de raciocínio e de conhecimento. A partir daí, elevou-se a necessidade de atualizar o conteúdo do ensino, a fim de integrar as novas descobertas científicas e tecnológicas e, também, aplicar o conhecimento na produção de novas ferramentas de aprendizagem. As novas características do saber e do trabalho mudam os perfis e as competências existentes, levando o mundo do trabalho a formular novas exigências ao sistema educativo. Essas inovações trazidas pelas TIC's colocam também a necessidade de se abrir novas áreas de formação que possibilitem qualificar os profissionais no ritmo das alterações referentes a suas especialidades.

A formação humana (específico-geral) é essencial ao processo de construção da cidadania e à inserção do indivíduo no mundo do trabalho ou "mundo da vida". Sem dúvida, as exigências dessa formação não cessam de aumentar em razão da complexidade das sociedades, das dificuldades de inserção profissional de jovens não-qualificados, da não-inclusão e da luta pela competitividade. Esses desafios alteraram o ambiente educacional/informacional e os meios postos à disposição dos/as docentes para o exercício da formação profissional, levando a universidade e seus docentes a se conscientizarem do papel da educação em relação aos novos meios de acesso à informação disponível fora da instituição.

Uma proposta de construção de um projeto educativo para cursos de formação de profissionais que pensam-conhecemagem sobre a informação terá de ser processual no ensino superior, exigindo a elaboração de planos de cursos e atividades extracurriculares e buscando, sobretudo, o envolvimento de discentes (aprendentes) e docentes (ensinantes) com a qualidade da educação e do ensino. Esse projeto deve ser construído como uma prática social e cultural, técnica e política, e mobilizadora de sujeitos multifuncionais e pró-ativos para exercer ações como profissionais qualificados e capazes de se adaptarem ao novo mundo do trabalho.

Os alicerces desse projeto educativo, que atendam às reais necessidades da sociedade da informação, conhecimento e aprendizagem, estão implícitos na idéia da educação como uma prática social e cultu- 
ral concreta, na qual todos os sujeitos estejam envolvidos. Do nosso ponto de vista, esses alicerces supõem que os participantes desse processo possam estar instrumentalizados por competências e habilidades necessárias à formação do profissional da informação, implicando a necessidade de se ter o próprio conceito de projeto educativo, desvinculado da concepção restrita que o entende como o fim de um processo de ensino. Essa preocupação conceitual terá de estar voltada para a participação, o engajamento e o compromisso da comunidade universitária.

A tessitura de um projeto educativo, a rigor, impulsiona um movimento coletivo em que os sujeitos (docentes, discentes, coordenação e chefes de departamento etc) interajam, para fazer parte dos vários momentos de sua construção. Implica construir não simplesmente uma grade de conteúdos e técnicas, mas também prestar atenção às práticas sociais, culturais, políticas e gerenciais que se expressam em seu desenvolvimento, às condições estruturais, organizativas, materiais que se dirigem a docentes/discentes, servindo-se de determinados meios para desconstruir as concepções distorcidas do ato formativo (GIMENO SACRISTÁN, 1998).

Um projeto para cursos de formação de profissionais que pensam-conhecemagem sobre a informação deverá pressu- por a captura de saberes que ajudem a organizar política, social. cultural e pedagogicamente as atividades educacionais e informacionais de modo claro e em consonância com as mudanças propostas na atual LDB e sua proposta de flexibilização exigida pela sociedade da informação, conhecimento e aprendizagem. Deve ser projetado como um "guarda chuva" para acoIher, de modo unitário e orgânico, a função tripartite da universidade, ou seja, ensino, pesquisa e extensão. Essa construção deverá partir de uma orientação segundo a qual os sujeitos do conhecimento são considerados nas suas experiências sociais e culturais.

O tecido do projeto educativo de um curso de formação de profissionais que pensam-conhecem-agem sobre a informação deverá acolher dois blocos de conteúdos: básicos e complementares. Os conteúdos básicos devem reunir as disciplinas de natureza epistemológica, históricosocial e conceitual, consideradas essenciais ao desenvolvimento de competências e habilidades requeridas para egressos do curso, com duração de dois semestres. Os conteúdos complementares (obrigatórios, optativos e eletivos) devem reunir as disciplinas específicas para o desenvolvimento de competências e habilidades que aprofundem os conteúdos básicos, avançando na capacitação do exercício da profissão, com duração de 06 (seis) semestres. Es- 
ses conteúdos deverão ser distribuídos por áreas, de acordo com as habilitações definidas no projeto educativo.

Para Gimeno Sacristán (1998), as renovações conteudísticas, no entanto, implicam mudanças de procedimentos e processos educativos com conteúdos de cultura. Neles devem estar implícitos os saberes que advogam a tese de que todo conhecimento está sujeito ao erro e à ilusão. Portanto, o conhecimento oferecido por aqueles/as que atuam em cursos de profissionais que pensam-conhecem-agem sobre a informação terá de ser visto como uma atividade preparatória para enfrentar os riscos permanentes de equívocos pois, sendo esse conhecimento considerado fruto de uma tradução muitas vezes mal feita e de uma reconstrução débil, pode trazer alguns desvios na linguagem que 0 transmite (MORIN, 2003).

Para superar os equívocos ou erros que travam o projeto da educação do futuro, impedindo de antevermos o perigo do conhecimento imposto, como certo, Freire (1999) defende a formação permanente de quem educa e de quem informa. Essa formação requer, desde o início, o significado do projeto educativo.

Construir um projeto educativo exige dos sujeitos envolvidos a compreensão de que a educação na sociedade do conhecimento "é o elemento-chave na edificação de uma sociedade baseada na informação, no conhecimento e no aprendizado" (TAKAHASHI, 2000, p. 45). Significa compreender a educação como um lugar de incertezas em que o/a docente vive a certeza de que o ato educativo implica não apenas ensinar os conteúdos, mas também ensinar a pensar certo (FREIRE, 1999).

\section{AO TECERMOS UM PROJETO, É FUNDAMENTAL CERCAR O TERMO}

O termo "projeto" estabelece ligação com o verbo projetar que "significa lançarse para frente, antever um futuro diferente do presente; pressupõe uma ação intencionada com um sentido definido, explícito, sobre o que se quer inovar" (GADOTTI, 2000 , p. 37). Especificamente, o projeto educativo é um processo inconcluso, construído de forma inter/multi/transdisciplinar que toma a autonomia, o diálogo, o respeito ao outro e a participação como pressupostos imprescindíveis a uma formação humana integral. Sua construção, segundo Gadotti (2000, p. 37), deve apoiar-se "no desenvolvimento de uma formação crítica; no envolvimento das pessoas: a comunidade interna e externa [à universidade]; na participação e na cooperação das várias formas do governo; e na autonomia, responsabilidade e criatividade como processo e como produto do projeto". É um pro- 
cesso permanente de reflexão, que se aproxima de um campo democrático de decisões em sua forma de organizar o trabaIho pedagógico dos cursos de formação.

O projeto educativo deve supor um processo de formação capaz de repercutir a importância e a necessidade do planejamento na educação para a cidadania. Isso implica concebê-lo não simplesmente como um conjunto de objetivos, metas, procedimentos e técnicas que emanam de uma autoridade superior, mas, sim, como uma prática social e cultural, essencialmente voltada para o compromisso político e institucional, que se articula aos interesses concretos de todos os sujeitos que estão participando dessa construção (GADOTTI, 2000).

Vasconcelos (2002), por sua vez, entende que o projeto educativo é a sistematização contínua de um processo de planejamento participativo, que se atualiza e se objetiva na caminhada, na qual se define o tipo de ação educativa que se quer realizar, a partir de um posicionamento quanto à sua intencionalidade, e de uma leitura da realidade.

Para o educador Paulo Freire não existem projetos neutros. O papel dos/as educadores/as é o de intervir, liderar e suscitar, agindo sempre com autoridade, mas respeitando o espaço do outro nas decisões pedagógicas. Essa construção freireana passa pela dimensão política do projeto, vez que, segundo ele, todo projeto pedagógico é político e ideológico. Essa dimensão política aparece no momento em que docentes e discentes a percebem como uma prática especificamente pedagógica, constituindo uma outra dimensão que reside na possibilidade de concretização da ação intencional da formação.

\section{5 É PRECISO COMPREENDER QUE O CURRÍCULO NÃO É GRADE}

O Livro Verde estabelece uma crítica à situação dos currículos nacionais, sugerindo a urgência de uma revisão curricular em todos os níveis e áreas. De modo particular, chama a atenção para as Ciências da Informação, afirmando que, no nível de graduação, "o típico currículo de Ciências da Informação reflete uma visão da área que foi atropelada em muitos aspectos essenciais (alguns para bem, outros para mal) pela revolução das tecnologias de informação e comunicação". (TAKAHASHI, 2000, p. 49).

Por outro lado, são surpreendentes as preocupações que o MEC começa a ter com a participação de vários segmentos acadêmicos na reestruturação do currículo dos cursos de formação em nível nacional. Este fato é novo, pois, durante anos, os currículos resultaram sempre de propostas geradas nos gabinetes dos burocratas da 
educação, sob a orientação de suas próprias ideologias e não em função de um projeto participativo, que respeitasse a autonomia das universidades diante dos próprios cursos. Embora essa nova postura possa representar um avanço para a educação brasileira, principalmente para os cursos de profissionais que pensamconhecem-agem sobre a informação (Biblioteconomia, Ciência da Informação e Arquivologia), é preciso estar vigilantes quanto aos "não ditos", pois, certamente, as estratégias de ontem estão metamorfoseadas nos entremeios do discurso de hoje. É dessa preocupação que deve imbuir-se os/as construtores/as do projeto educativo. Isso supõe concebê-lo como uma prática social, cultural e histórica em que dela participam criticamente, os sujeitos do conhecimento: o/a docente e o/a discente.

As reflexões de Gimeno Sacristán (1998) ajudam a captar os implícitos, subtendidos e pressupostos que norteiam as atuais políticas de reestruturação curricular embasadas num paradigma, em que "muitos tipos de ações intervêm em sua configuração, esquecendo que esse processo ocorre dentro de certas condições concretas e se configura dentro de um mundo de interações culturais e sociais" (GIMENO SACRISTÁN, 1998, p. 21).

A construção de um currículo como parte do projeto educativo é resultante de uma prática social que "expressa determinações não estritamente escolares, algo que se situa entre as experiências pessoais e culturais dos sujeitos" (GIMENO SACRISTÁN, 1998, p.22). Este autor afirma que a qualidade do ensino formativo somente será possível se mudarmos os conteúdos, os procedimentos e os contextos de realização dos currículos. O currículo, em nossa concepção, é parte intrínseca do projeto educativo, devendo haver coincidência entre o projeto e o conceito de currículo, desde que se associem a ele todas as atividades educativas (SANTOS, 1994).

O currículo é a operacionalização das atividades de ensino, abrangendo em seu desenvolvimento uma concepção de sujeito e de mundo, o conteúdo, o ensino, a metodologia, a pesquisa, a extensão e a avaliação. Essa complexidade pressupõe uma formação humana, plurifacetada e uma formação técnico-científica, que contribua para colocar o profissional no patamar exigido pelas configurações científicas e tecnológicas do País.

Para Santos (1994), um currículo que atenda a tais exigências terá de estar dissociado de uma visão tecnicista, pois a objetividade e a neutralidade separam o sujeito do objeto, incorrendo num processo mecânico que, raramente, poderá explicar a realidade dos fenômenos curriculares para mudá-los. 
No caso específico de cursos de Ciência da Informação, Biblioteconomia e Arquivologia, os conteúdos curriculares poderão ser distribuídos por áreas e de acordo com as habilitações a serem definidas no próprio projeto educativo ou projeto político-pedagógico desses cursos. A estrutura curricular desses cursos deve refletir concretamente a função social desses campos de conhecimento e seu compromisso com a "educabilidade humana", refletindo o contexto global, regional, local, multidimensional e complexo. Seu projeto educativo deve intensificar a produção de conteúdos espelhada não apenas na nossa identidade, social e cultural, mas também considerar o diverso, o global.

Essa característica do projeto educativo é fundamental para inserção dos indivíduos na sociedade da informação, conhecimento e aprendizagem. Ė importante salientar que a construção dessa sociedade depende não exclusivamente das gestões institucionais, culturais e públicas com "suas plenas condições de uso das potencialidades das tecnologias, relativa à produção, difusão e disponibilização de conteúdos veiculadores ou construtores de identidade cultural" (TAKAHASHI, 2000), mas também exige indivíduos hábeis, flexíveis e competentes para pensar, conhecer e agir sobre a informação para transformá-la em conhecimento.
Para um curso em Ciência da Informação, que toma a informação como objeto de estudo, o seu currículo deve oferecer conteúdos que possam contribuir para delinear o perfil do profissional da informação que atuará nessa atual sociedade. Um currículo que permita a aquisição de competências para refletir sobre os fundamentos teórico-metodológicos da Ciência da Informação, a ética da informação, o papel e o uso das novas tecnologias e a compreensão do outro; um currículo que se mostre como um campo de possibilidades adequadas ao lugar em que se processam as transformações. Nessa concepção de currículo, há de se repensar a formação humana como um processo contínuo e permanente, não somente para que se dê a interação entre o saber prático e o saber teórico de uma ocupação. Necessita-se também desenvolver uma identidade cultural, entendida como a soma de significados que estruturam a vida de um indivíduo (TAKAHASHI, 2000) e indispensáveis aos aspectos pessoal e profissional.

Esse currículo deve estar inserido num projeto educativo que assuma o processo ensino-aprendizagem na perspectiva dos objetivos, diretrizes pedagógicas, políticas, técnicas, científicas e sociais articulados aos conteúdos centrados na realidade global, regional e local. É evidente que o projeto terá de refletir não exclusivamente o caráter que a sociedade tecnológica 
está assumindo, mas voltar-se a uma transformação importante de toda relação pedagógica baseada num "princípio educativo". Esta idéia supõe que a prática educativa ou informacional não deve ser realizada individualmente, uma vez que educar em Ciência da Informação é um trabalho coletivo com finalidades específicas de geração, tratamento, disponibilização, uso e produção de sentido.

A interação do sujeito com a informação deverá ocorrer num contexto em que os conteúdos específicos e diversificados do ensino possam ser construídos e transformados em conhecimento para atender as diversas demandas sociais e culturais em suas nuanças inovadoras e produtoras do saber. Devido a isso, o projeto educativo deve englobar uma compreensão de currículo que se dicotomiza do ensino como apenas a apropriação dos conceitos científicos ou como um simples processo de transmissão de fatos e informações e utilização de técnicas e recursos educativos, para considerar a participação próativa de docentes e discentes como sujeitos-cidadãos, aprendentes e construtores do conhecimento na busca de conhecimentos científicos e formativos que visem atender suas necessidades informacionais emergentes e permanentes (AQUINO, 2004).
Dentre outros saberes necessários à formação do profissional da informação que conhece-pensa-age sobre a informação, o projeto educativo terá de atentar para um currículo em que o conceito de informação vislumbre a busca da reflexão permanente sobre a qualidade das práticas educacionais e informacionais, a geração de competências e habilidades e a produção científica, com vistas a contribuir com a apreensão da informação tendo como prioridade o desenvolvimento do local para o global e vice-versa e as necessidades humanas básicas da população como um todo. É premente um currículo que extrapole os saberes técnicos e científicos para uma conjugação de saberes que se volta para a sensibilização e solução de problemas que interceptam o desenvolvimento humano.

Os cursos de graduação precisam compor um currículo que informe a alunos/as sobre os problemas da realidade local e global, desviando a atenção do/as alunos/as da "cultura da cegueira e do esquecimento", pois o objetivo da informação - via leituras, debates, conversas, seminários - e da formação, é impulsionar uma reflexão crítica sobre as próprias experiências (SEQUEIROS, 2000) vivenciadas.

De acordo com os parâmetros da proposta curricular estabelecida pelo MEC para cursos de graduação, o projeto edu- 
cativo terá de desenhar uma formação profissional que tenha acesso a conteúdos que atendam aos princípios da especificidade (área pela qual o/a aluno/a fez opção) e da flexibilidade curricular, permitindo assim que se estabeleça a diversidade pretendida na própria formação. Este projeto deverá prever a busca da atualização permanente de conteúdos e processo de ensino-aprendizagem, com o uso das tecnologias da informação e da comunicação TIC's que possibilitarão uma atuação profissional contextualizada com os avanços da ciência e da técnica.

No projeto educativo, os espaços de atuação desses profissionais terão de ser considerados como instâncias fundamentais que atuarão como um indicador da qualidade do curso na formação. Ao postular que o currículo é um lugar privilegiado para uma análise da comunicação entre idéias, valores e prática, Gimeno Sacristán (1998) proporciona uma oportunidade para realizarmos uma integração importante: a graduação e a pós-graduação.

\section{A LINHA DE CONEXÃO: GRADUAÇÃO E PÓS-GRADUAÇÃO}

A formação de profissionais que pensam-conhecem-agem sobre a informação também se concretiza com parceria da pós-graduação estabelecida com a graduação, que exigirá o desenvolvimento de atividades de ensino e pesquisa voltadas para o fortalecimento dessa interação. Para tanto, os programas de Pós-Graduação deverão formular propostas de parcerias, através de: a) estágio-docência (alunos da pós-graduação no ensino de graduação); b) cursos de capacitação para os docentes; c) participação em eventos científicos para comunicação de pesquisas (concluídas ou/em andamento); d) seminários, workshops e palestras, partir das linhas de pesquisa; participação de alunos/as regulares e voluntários em atividades de iniciação científica.

É imprescindível, sobretudo, a constituição de espaços institucionais que envolvam alunos/as de graduação, pósgraduandos/as e profissionais da área em atividades de pesquisa por meio de projetos (PIBIC, PROLICEN, PROBEX etc.) com vistas a permitir um processo de reflexão crítica e troca de experiências que considere a interlocução entre a universidade e a sociedade.

Essa parceria é desejável porque a interação permitida contribui para a aceitação do diálogo, autonomia e reconhecimento dos limites e falhas de cada um, implicando a complexidade do ato de ensinar (informar) que envolve as relações inter/intradisciplinares com alunos/as de cursos e/ou áreas do conhecimento similares, e serve para atender ao formato tecnológi- 
co imposto pela sociedade de informação à formação do indivíduo. Nesse sentido, Pourtois e Desmet (1999) afirmam que o debate e o combate entre eles são inevitáveis e suscetíveis de desestabilizar as nossas referências e questionar as certezas.

A conexão da graduação com a pósgraduação é o resultado consciente do intercâmbio entre as "alteridades múltiplas”, e só pode ser vista em relação com o contexto prático em que se realiza, e que está multicondicionado por fatores de diversos tipos, que se convertem em agentes ativos do diálogo entre o projeto $\mathrm{e}$ a realidade (POURTOIS; DESMET, 1999). Essa conexão aponta para novos horizontes da produção de conhecimento no desenvolvimento local em que o profissional da informação desnuda-se de seu caráter eminentemente técnico, passando a ser concebido como sujeito capaz de fornecer as condições de produção adequadas, a fim de que os/as alunos/as possam tomar posse da informação para ressignificá-la e transformá-la em conhecimento na perspectiva de contribuir para o desenvolvimento local, efetivando, assim, a construção da cidadania.

Na pós-graduação, a proposta de integração desses cursos terá de ocorrer mediante o estabelecimento de definição de linhas de pesquisa cujos temas trabaIhados possam oferecer fundamentos, subsídios para o desenvolvimento de ambientes de informação; geração, tratamento e uso da informação; promoção e disseminação da cultura; preservação da memória, diversidade cultural e cidadania; estudo de políticas públicas de informação com vistas à gestão e uso de serviços e produtos de informação em ambientes de informação.

É condição fundamental para 0 desenvolvimento de uma universidade, a proposta de articulação entre ensino, pesquisa e extensão, que deverá ser garantida não só pelas atividades de ensino, mas pela execução de projetos que possibilitem uma infra-estrutura física e equipamentos geradores de tecnologias sofisticadas.

Essa é a realidade que deverá caracterizar o profissional da informação e a Ciência da Informação na sociedade da informação rumo à sociedade do conhecimento e da aprendizagem, delineando novas competências e habilidades para agir no ensino de graduação e contribuindo para uma expansão do campo profissional. No entanto, a integração implicará a interação com as TIC's como ferramentas para toda e qualquer área de atuação profissional.

A construção do projeto educativo deve voltar o olhar para a gestão da informação numa atitude interdisciplinar, plurisdisciplinar, transdisciplinar e disciplinar, com pressupostos teórico-metodológicos 
de áreas como Administração, Arquivística, Diplomática, Lógica, Lingüística, Comunicação, Educação, Psicologia, Sociologia, e outras disciplinas que contribuem para o desenvolvimento das atividades do profissional da informação. Além disso, é preciso conceber a pesquisa como elemento fundamental para a qualidade do ensino de graduação, permitindo ao sujeito do processo educativo uma vivência da atividade de investigação em um contexto acadêmico. Um dos saberes necessários à construção do projeto educativo é proposto por Paulo Freire que compreende bem a relação do ensino com a pesquisa:

Não há ensino sem pesquisa e pesquisa sem ensino. Esses quefazeres se encontram um no corpo do outro. Enquanto ensino, continuo buscando, reprocurando. Ensino porque busco, porque indaguei, porque indago e me indago. Pesquiso para constatar, constatando, intervenho, intervenho, intervindo educo e me educo. Pesquiso para conhecer o que ainda não conheço e comunicar ou anunciar a novidade (FREIRE, 1999, p.32).

A educação permanente é compromisso da universidade com a formação do/a aluno/, pois esta formação extrapola os limites da educação formal. Na construção do projeto, deve-se levar em conta que as disciplinas optativas, quando bem planejadas e qualitativamente trabalhadas podem se constituir em excelentes instrumentos para o ingresso de alunos/as graduados/as. Esse instrumento deve incorpo- rar a preocupação em dar ao/a aluno/a uma visão complexa do currículo, em que os conteúdos interdependem e concorrem para o objetivo final da educação - a formação do profissional da informação - em suas diferentes, mas complementares áreas de atuação junto ao campo informacional. Essa formação não anula a importância da capacidade científica, pedagógica e ética daqueles/as que atuam na educação para operacionalizar o currículo, respeitando o/a educando/a em suas diferenças.

A atual perspectiva dessa conexão resgata a concepção de estágio como um espaço de vivência profissional, em que o/a educando/a tem a oportunidade de aplicar os conteúdos adquiridos na formação em situações concretas. O estágio terá de contemplar objetivos pedagógicos próprios, com especial ênfase a questões ligadas à atuação profissional (postura ética, movimento associativo, atualização etc). Sem perder de vista a importância do currículo como uma prática social, cultural, política e pedagógica e o interesse de cada aluno, sugere que as disciplinas estejam voltadas para os conteúdos fundamentais, permanecendo as disciplinas optativas (objeto de cuidadoso planejamento) como uma forma de o/a educando/a se aprofundar em áreas específicas de seu interesse. Por outro lado, é fundamental que as instituições de ensino, enquanto instâncias acadêmicas atuem junto a comissões, projetos de pes- 
quisas interinstitucionais, eventos, cursos e órgãos científicos e pedagógicos e de classe, em nível nacional e internacional, para garantir a necessária "oxigenação", a integração e o intercâmbio de informações e, assim, evitar isolacionismos.

O espectro da sociedade da informação, a literatura especializada, os núcleos temáticos, os debates, a proposta curricular estabelecida pelo MEC, as discussões desencadeadas pela Associação Brasileira de Educação em Ciência da Informação (ABECIN), os encontros regionais com docentes (bibliotecários e cientistas da informação) de diversos estados do Norte/Nordeste e as experiências vividas pelos/as docentes ajudam a fortalecer a construção de um projeto nos cursos de formação de profissionais que pensamconhecem-agem sobre a informação.

Os cursos de formação sobre a informação deverão considerar a educação mediada pelas TIC's, e seus conteúdos para uma formação adequada de docentes. Educar na sociedade da informação rumo a sociedade do conhecimento extrapola treinar as pessoas para o uso das TIC's, pois trata-se de investir na criação de competências para atuar na produção de bens e serviços, tomar decisões, operar com fluência os novos meios de comunicação e ferramentas nas suas atividades e saber aplicar criativamente as novas mí- dias "Trata-se também de formar os indivíduos para 'aprender a aprender', de modo a serem capazes de lidar positivamente com a contínua e acelerada transformação da base tecnológica" (TAKAHASHI, 2000, p. 45).,

A formação dos indivíduos deve estimulá-los na busca de elementos que the possibilite uma melhor compreensão do contexto social e cultural da produção, disseminação e uso da informação em sua própria região. Isto significa, do nosso ponto de vista, dar um outro significado ao ato de educar (informar) na sociedade de informação.

\section{CONSIDERAÇÕES FINAIS}

No Brasil, o sentido da educação em Biblioteconomia e Ciência da Informação precisa estar em consonância com a economia global em que a produtividade exige um indivíduo com formação sólida e renovada "capaz de saber pensar, de participar de processos decisórios, de avaliar qualidade dos processos, formular raciocínio lógico-abstrato e discutir com argumentalidade, [que Ihe permite] refazer-se e repensar-se" (TAKAHASHI, 2000, p. 40).

O projeto educativo desses cursos precisa construir um currículo inserido em seu tempo, que é atual e histórico. É o tempo que está em sintonia com as exi- 
gências informacionais e tecnológicas.

Neste empreendimento pedagógico, o currículo deve atender às características regionais, fornecendo as condições aos profissionais de saberem produzir um conhecimento ativo, construtivo e pró-ativo, a fim de operarem no cenário globalizado da cultura moderna. O projeto educativo, Ionge de centrar-se numa prática assistencialista e de apropriação de estoques de saberes, terá de desenvolver habilidades e competências para enfrentar os desafios que a realidade impõe, e questionar o que sabe, buscando a informação certa permanentemente, a partir de uma pedagogia da informação.

\section{REFERÊNCIAS}

AQUINO, M. A. Educação e tecnologia: desenlaces/ (entre) laços na aventura de (in) formar o homem: uma discussão possível? Informação\&sociedade, João Pessoa, v. 5, n. 1, p. 29-43, 1995.

AQUINO, M.A. Ecologia informacional: da árvore da informação ao rizoma do conhecimento. Desafios para formação humana na sociedade da aprendizagem. João Pessoa: UFPB, 2004, 229p. Tese (Professor Titular) - Centro de Ciências Sociais e Aplicadas, Departamento de Biblioteconomia e Documentação Universidade Federal da Paraíba, João Pessoa, 2004.

ASSMANN, Hugo. A metamorfose do aprender na sociedade da informação. Ciência da Informação, Brasília, v. 29, n. 2, p. 5-13, maio/ago, 2000.
ASSMANN, H.; MO SUNG. J. Competência e sensibilidade solidária. São Paulo: Vozes, 2000.

BLANCHET, René. Conhecimento da terra e educação. In:MORIN, Edgar. A religação dos saberes: o desafio do século XX, Rio de Janeiro: Bertrand do Brasil, 2002.

DEMO, P. Conhecimento moderno: sobre ética e intervenção do conhecimento. Petrópolis, 1998.

DEMO, P. Desafios modernos da educação. Petrópolis:Vozes, 1995.

FREIRE, P. Pedagogia da autonomia: saberes necessários à prática educativa. São Paulo: Paz e Terra, 1999.

GADOTTI, M. Perspectivas atuais da educação. Porto Alegre: Artes Médicas, 2000.

GRISPUN, M. P. S. (Org.). Educação tecnológica. São Paulo: Cortez, 2001.

GIMENO SACRISTÁN, J. O currículo: uma reflexão sobre a prática. Porto Alegre: ArtMed, 1998.

MORIN, E. O Método 2: a vida da vida. Porto Alegre: Sulina, 1999.

MORIN, E. Os desafios da complexidade. In: _. A religação dos saberes: o desafio do século XX. Rio de Janeiro: Bertrand do Brasil, 2002.

MORIN, Edgar. Sete saberes necessários à educação do futuro. Rio de Janeiro: Paz e Terra, 2003.

MOORE, Nick. A sociedade da informação. In: INSTITUTO BRASILEIRO DE INFORMAÇÃO EM CIÊNCIA E TECNOLOGIA. A informação: tendências para o novo milênio. Brasília: IBICT, 1999.

PENTEADO, Heloísa Dupas. Pedagogia da comunicação: sujeitos comunicantes. São Paulo:Cortez, 1998. 
POURTOIS, J. P.; DESMET, H. A educação pós-moderna. São Paulo: Loyola, 1999.

SEQUEIROS, Leandro. Educar para a solidariedade: projeto didático para uma nova cultura de relações entre os povos. Porto Alegre: Artmed, 2000.

TAKAHASHI, Tadao (Org.). Sociedade da informação: livro verde. Brasília: MCT, 2000.

VASCONCELOS, E.M. Complexidade e pesquisa interdisciplinar: epistemologia e metodologia operativa. São Paulo: Vozes, 2002.

Mirian de Albuquerque Aquino

Professora do Departamento de Biblioteconomia e Documentação (UFPB). Doutora em

Educação

miriabu@gmail.com

\section{Title}

The Curriculum Construction in partnership with the Educative Project

\footnotetext{
Abstract

Proposes some reflection concerning the curriculum construction in accordance to the educative project facing the recent technological changes. Inserts some discussions which articulate both education and information focusing possible changes in the human's formation studies. Reports the complex concepts of knowledge defined by Edgar Morin and Paulo Freire's contribution to construct an information pedagogy as an alternative to reduce the emphasis on a repetitive teaching and also the conventional techniques. The paper proposes an interaction between teachers and students with the new methods of teaching. It connects some authors' ideas and discussions concerning the information and communication technologies and their relation with education.
}

\section{Keywords}

University; Educative Project; Curriculum; Knowledge Society.

\section{Título}

La construcción del curriculum en sociedad con el proyecto educativo

\section{Resumen}

El presente texto propone reflexionar sobre la construcción de un curriculum en sintonía con el proyecto educativo frente al escenario de los cambios tecnológicos. Inserta una discusión que articula educación e información visualizando los posibles cambios en la realidad de los cursos de formación humana. Mobiliza la complejidad de los saberes morinianos y las contribuciones freireanas para elaborar una pedagogía de la información como una alternativa que ayude a reducir el énfasis en la enseñanza repetitiva y sus técnicas convencionales. Propone una interacción de los educadores y educandos confrontándose con las nuevas formas de aprendizaje. Hace un "link" con autores que discuten las tecnologías de la información y comunicación y su relación con el proyecto educativo.

\section{Palabras Clave}

Universidad; Proyecto Educativo; Dilema Ético; Sociedad del conocimiento.

Recebido em: 06.11.2006

Aceito em: 24.11.2006 